\title{
ANÁLISE DA RENTABILIDADE DAS MAIORES COOPERATIVAS AGROINDUSTRIAIS BRASILEIRAS NO ANO DE 2016 POR MEIO DA ANÁLISE ENVOLTÓRIA DE DADOS
}

Wanderson Dutra Gresele

Franklin Ângelo Krukoski ${ }^{2}$

Danieli Inês Reitz ${ }^{3}$

\begin{abstract}
Resumo: $O$ objetivo desta pesquisa é identificar e analisar as cooperativas agroindustriais brasileiras que apresentaram melhores desempenhos em 2016, a partir da Análise Envoltória de Dados. A escolha dos inputs e outputs deu-se com base método de análise de rentabilidade denominado sistema Du Pont. Após a sintetização dos inputs e outputs e aplicação do método de seleção de variáveis I-O Stepwise Exaustivo Completo, estabeleceram-se como inputs sobras líquidas, ativo total, passivos e patrimônio líquido e como output o retorno sobre o capital empregado. Após a aplicação do modelo DEA-BBC, orientado a outputs, destacaram-se como eficientes as cooperativas Holambra, Coamo, Cooxupé, Coopavel e Copagril, com destaque a primeira, eficiente tecnicamente e em escala. Foram identificadas as cooperativas ineficientes e sugeridos benchmarks.
\end{abstract}

Palavras-Chave: Cooperativas; Eficiência; Análise Envoltória de Dados.

\section{ANALYSIS OF THE PROFITABILITY OF THE LARGEST BRAZILIAN AGRO- INDUSTRIAL COOPERATIVES IN 2016 THROUGH DATA ENVELOPMENT ANALYSIS}

\begin{abstract}
Abrstact: This article sought to identify the Brazilian Agroindustrial Cooperatives that presented the best performance in 2016, based on Data Envelopment Analysis. The choice of inputs and outputs was based on the rentability analysis method called the Du Pont system. After the synthesis of the inputs and outputs and application of the I-O Stepwise method, we established as inputs: leftovers, total assets, liabilities and shareholders' equity and as output the return on capital employed. Following the application of the DEA-BBC, output-oriented model, the cooperatives Holambra, Coamo, Cooxupé, Coopavel and Copagril were highlighted as being efficient, especially the first, technically efficient and in scale. We identified inefficient cooperatives and suggested benchmarks.
\end{abstract}

KEYWORDS: Cooperatives; Efficiency; Data Envelopment Analysis.

\section{ANÁLISIS DE LA RENTABILIDAD DE LAS COOPERATIVAS AGROINDUSTRIALES BRASILEÑAS MÁS GRANDES EN 2016 A TRAVÉS DEL ANÁLISIS DE ENVOLTURA DE DATOS}

Resumen: El objetivo de esta investigación es identificar y analizar las cooperativas agroindustriales brasileñas que tuvieron un mejor desempeño en 2016, con base en el Análisis de Envoltura de Datos. La elección de entradas y salidas se basó en un método de análisis de rentabilidad llamado sistema Du Pont. Después de sintetizar las entradas y salidas y aplicar el Método de Selección Integral Variable Paso a Paso I-O, las sobras netas, los activos totales, los pasivos y el patrimonio se establecieron como las salidas y el rendimiento del capital empleado. Después de la aplicación del modelo DEA-BBC, orientado a los resultados, las cooperativas Holambra, Coamo, Cooxupé, Coopavel y Copagril se destacaron como eficientes, con énfasis en la primera, técnicamente eficiente y a escala. Se identificaron cooperativas ineficientes y se sugirieron puntos de referencia.

Palabras clave: Cooperativas; Eficiencia; Análisis de envoltura de datos.

\footnotetext{
${ }^{1}$ Mestre em Administração pela Universidade Federal do Paraná - UFPR. Docente na Universidade Estadual do Oeste do Paraná - UNIOESTE; (wanderson.gresele@hotmail.com)

2 Mestre em Métodos Numéricos em Engenharia pela Universidade Federal do Paraná - UFPR. Docente na Universidade Estadual do Oeste do Paraná - UNIOESTE; Mestre em Matemática (franklin.krukoski@gmail.com)

${ }^{3}$ Bacharel em Administração Universidade Estadual do Oeste do Paraná - UNIOESTE; (danielireitz@gmail.com)
} 


\section{Introdução}

O problema central de qualquer organização é a escassez dos recursos, por isso os gestores tomam decisões na busca tirar o maior retorno dos recursos disponíveis. A eficiência tem a ver exatamente com isso: obter o maior benefício possível de uma quantidade de recursos. (MATTOS e TERRA, 2015a)

Em face da escassez e na busca de eficiência, diversos agentes geralmente chegam à conclusão que certa atividade se torna por demais custosa para cada um isoladamente, assim eles se agrupam em uma sociedade dotada de características especiais, chamada de organização cooperativa. Essa se torna um intermediário entre o mercado e os agentes cooperados para promover seu incremento. (BIALOSKORSKI NETO, 2014).

Diferentemente das sociedades de capital, as sociedades cooperativas são caracterizadas pelo ato cooperativo, onde há a agregação inicial do fator de produção de trabalho, não do fator de produção capital. Mas esses dois tipos de sociedade comungam de algumas características em comum: primeiramente elas operam no mesmo tipo de mercado capitalista, mesmo elas tendo característica diferentes; e, em segundo, devem buscar a máxima eficiência econômica, as sociedades de capital para a remuneração dos seus investidores e as sociedades cooperativas para que possa manter a prestação de serviços aos seus cooperados, ou seja, o trabalho, não o lucro, como em uma firma em comum. (ROSSETI, 2011; MANKIW, 2012; BIALOSKORSKI NETO, 2014)

O setor cooperativista é dividido por ramos. Um que se destaca no Brasil é o agropecuário. Segundo a Organização das Cooperativas do Brasil (OCB, 2018) e a Organizações das Cooperativas do Paraná (OCEPAR, 2018) o ramo agropecuário envolve as cooperativas de produtores rurais, agropastoris e de pesca, cujos meios de produção estão nas mãos dos cooperados. Estima-se que cerca de $48 \%$ de tudo que é produzido no meio rural brasileiro passa, de alguma forma, por uma cooperativa e envolve mais de 1 milhão de pessoas.

Apesar da importância para o cenário nacional, as organizações cooperativas passam hoje, como apresenta Bialoskorski Neto (2015), por uma série de reflexões e crises, devido a própria evolução do mercado no qual estão inseridas. Uma das principais reflexões traz à tona o aspecto gerencial, em virtude de manter a eficiência na geração de serviços aos cooperados, ou ainda, buscar a eficiência em face dos escassos recursos que possuem. Neste caminho a análise da eficiência das cooperativas, que pode ser por meio da eficiência social e ou da eficiência financeira, se torna uma necessidade latente. Assim, este artigo tem como foco análise da eficiência financeira das organizações cooperativas, mais especificamente as agroindustriais. 
A eficiência não é um tema novo na gestão. Aliás, a origem da administração se deu pela necessidade de melhor alocação dos recursos das organizações. $\mathrm{O}$ processo de análise de eficiência fornece uma comparação dos desempenhos de unidades tomadoras de decisões (DMU's) com aquelas que apresentam altos padrões de eficiência. Assim, o presente artigo utilizou-se de dados financeiros das maiores cooperativas agroindustriais do país e do método de análise envoltória de dados, também conhecido como DEA, de Data Envelopment Analysis, para encontrar índices de eficiência relativa para unidades de análise.

Dessa forma, o objetivo geral da pesquisa, seja ele "identificar as cooperativas agroindustriais brasileiras que apresentaram melhores desempenhos em 2016, dada a metodologia DEA", será atingido ao calcular as eficiências relativas das maiores cooperativas brasileiras, pelo método DEA orientado ao output; identificar as cooperativas com ineficiências técnicas ou de escala, destacando os retornos variáveis de escala e apontar cooperativas referências (benchmarks) às ineficientes.

\section{Referencial Teórico}

\section{O Cenário do Cooperativismo Agroindustrial}

Cooperação não é um tema recente na humanidade. A doutrina cooperativista surgiu posteriormente às realizações práticas. Pioneiros de Rochdale é como são conhecidos os organizadores da primeira cooperativa de consumo com a estrutura e as normas conhecidas até hoje. Eram vinte e oito tecelões da cidade de Rochdale, Inglaterra, que em novembro de 1843 reuniram-se em assembleia com o propósito de encontrar um meio para melhorar sua situação econômica.

Além de ter uma iniciativa grandiosa, os Pioneiros de Rochdale deixaram como herança estatutos que contém princípios do funcionamento e da estrutura da sociedade cooperativa. Estes princípios formaram a base para os fundamentos da doutrina cooperativista, que busca uma organização social mais equitativa e mais justa repartição.

No Brasil, ao contrário do que ocorreu na Europa, onde a doutrina cooperativista surgiu após a prática, as ideias precederam os atos. O movimento cooperativo brasileiro é relativamente recente, datando sua difusão sistematizada a partir de 1932.

A Legislação brasileira, mais propriamente o artigo $4^{\circ}$ da Lei Federal $N^{\circ}$ 5.764/71, entende que as organizações cooperativas são sociedades de pessoas, com forma e natureza jurídica próprias, de natureza civil, não sujeitas a falência, constituídas para prestar serviços aos associados. Elas se distinguem das outras tipificações de sociedades, principalmente, por ter adesão voluntária, variabilidade do capital social representado por quotas-partes, limitação do 
número de quotas-partes do capital para cada associado, singularidade de voto, quorum para o funcionamento e deliberação baseado no número de associados e não no capital, retorno das sobras líquidas do exercício, proporcionalmente às operações realizadas pelo associado, fundos de Reserva e de Assistência Técnica Educacional e Social.

As organizações cooperativas passam hoje em dia por uma série de reflexões e crises, devido a própria evolução (BIALOSKORSKI NETO, 2014). Assim, é importante destacar alguns aspectos que estão se tornando preocupações para a gestão das cooperativas na atualidade. De maneira sucinta, Oliveira (2003), sem estabelecer níveis de prioridade, destaca algumas expectativas para o setor, que são: o incremento do nível de cooperação entre pessoas, grupos, atividades e regiões pode possibilitar inclusive, uma cooperação nacional ou mesmo internacional; a ampliação e o fortalecimento do nível de concorrência entre as empresas de capital e as cooperativas; tendo em vista efetivar decisões ágeis e com preços competitivos às organizações cooperativas tenderão a possuir estruturas cada vez mais enxutas; o aumento de fusões entre cooperativas; o foco de poder está se direcionando para a ponta final do processo logístico da cooperativa, gerando uma maior preocupação com processos, trazendo assim a qualidade total, redução do nível de desperdício e preocupação com problemas ambientais; por fim, há ainda a aceleração da evolução tecnológica, redução do ciclo de vida dos produtos e negócios e a profissionalização de cooperados e de cooperativas.

Dado que as tendências que envolvem as cooperativas estão relacionadas ao mercado no qual estão inseridas, ou seja, um mercado de concorrência com empresas de capital, devemos ainda entender a problemática que envolve a economia da cooperação. Como exemplifica Bialoskorski Neto (2014), imagine a existência de um monopólio de uma empresa de capital e a formação de uma organização cooperativa. As duas com as mesmas características de produção. Sabe-se que a firma de capital monopolista vai maximizar seu lucro igualando seu custo marginal a sua receita marginal. Assim essa empresa estará oferecendo uma quantidade a um preço de acordo com a curva de demanda existente, dado o tipo de mercado.

Como o mercado está monopolizado os produtores buscam a organização da cooperativa, procurando maiores vantagens e preços menores. Essa poderia tender a fixar seu preço procurando o mínimo custo e menor preço ao cooperado, ou seja, o custo marginal é igual ao custo médio no ponto de mínimo custo. Assim, o preço da cooperativa mais baixo que o mercado gerará uma demanda não satisfeita, ou melhor, uma mudança na estrutura da demanda. Esta situação não é sustentável devido ao excesso de demanda e ainda porque a cooperativa não teria o mesmo "ganho extra" que a empresa de capital para realização de investimentos e, consequentemente, atendimento das demandas que emergem. Em resumo, a cooperativa não 
teria como investir em novas tecnologias, negócios, mercados, de modo tão eficiente quanto a empresa de capital, a menos que a cooperativa mantivesse a estratégia de eficiência da empresa de capital. (BIALOSKORSKI NETO, 2014).

Entretanto, se a cooperativa mantiver a estratégia de ganhos das empresas de capital ocorrerá um conflito entre sua razão de existência (no caso exemplificado, o preço elevado no mercado) e a prática. A solução então está no conceito de retorno das sobras líquidas, que permite a cooperativa operar num mercado, sem causar significativos impactos na estrutura de demanda, prever investimentos para a melhoria e ampliação dos serviços oferecidos e retornar os resultados através de uma distribuição proporcional de acordo com o trabalho e a operação de cada um (pro rata). (BIALOSKORSKI NETO, 2014).

Em face das tendências que vive o cooperativismo e da necessidade crescente de gerar serviços aos seus cooperados, essas organizações devem agir sobre os conceitos que permeiam o mercado, ou seja, de acordo com premissas de maximização de resultados, produtividade e eficiência. Para assim distribuir seus resultados, possibilitar os investimentos e melhorias no trabalho prestado.

Neste caminho Bialoskorski Neto (2014) sugere que um dos tópicos importantes para a gestão das cooperativas é a análise da eficiência. Ele sugere que a empresas cooperativas devem se atentar para a eficiência social, que é a capacidade de a cooperativa assegurar ao associada a obtenção de seus objetivos econômicos, e a eficiência financeira, que utilizam dos instrumentos tradicionais de análise, demonstrativos financeiros e índices de eficiência, respeitando as particularidades contábeis desses tipos de sociedades.

\section{Análise econômico-financeiro}

A análise financeira das organizações tem como foco extrair informações para o processo de tomada de decisões. De outro modo, essa análise busca transformar dados em informações, que podem produzir uma reação. O contador busca captar, organizar e compilar os dados, ou seja, organiza os eventos econômico-financeiros em demonstrativos e o processo de análise preocupa-se com a interpretação das informações contidas nos demonstrativos financeiros. (ASSAF NETO, 2001; LEMES JR., RIGO E CHEROBIM, 2010; MATARAZZO, 2017).

Dado sua importância e praticidade, o processo de análise do desempenho financeiro organizacional por meio das informações financeiras presentes nos demonstrativos não é recente, data do final do século XIX. A análise surgiu e se desenvolveu dentro das instituições bancárias, principalmente com a preocupação de analisar a capacidade de pagamento dos tomadores de empréstimos. (MATARAZZO, 2017) 
No geral, a análise econômico-financeira se baseia nas informações contábeis para compreender a posição econômico-financeira, as causas que determinaram a evolução apresentada e as tendências futuras e, se necessário, agir para melhorar os resultados. A análise desenvolvida adequadamente proporciona eficiência, rapidez e segurança aos gestores, que passam a avaliar melhor as diversas decisões a serem tomadas e o impacto delas decorrentes. (GITMAN, 2001; ASSAF NETO, 2014)

Quanto às técnicas, podemos desenvolver uma análise econômico-financeira por seis diferentes modos. A primeira, consiste na apuração de índices econômico-financeiros, que são relações entre valores dos eventos financeiros apresentados nos demonstrativos financeiros. Os índices costumam ser divididos em quatro categorias: índices de liquidez e endividamento, que mede a folga financeira da organização e a proporção de recursos de terceiros utilizados na composição do capital; índices de rentabilidade e lucratividade, que mede demonstram os retornos; e índices de atividade, que mensura a duração dos ciclos operacionais de uma empresa; e índices de valor adicionado, que leva em consideração o custo de oportunidade. (GITMAN, 2001; ASSAF NETO, 2001; LEMES JR., RIGO E CHEROBIM, 2010; MATARAZZO, 2017).

Em segundo, há a análise vertical e horizontal dos demonstrativos. Essas buscam o estudo de tendências, ou seja, busca entender o caminho no qual a organização está indo. A análise horizontal permite avaliar a evolução dos itens presentes nas demonstrações contábeis em intervalos de tempo sequenciais, enquanto a análise vertical permite conhecer as alterações ocorridas na estrutura dos relatórios analisados, considerando percentualmente as proporções existentes entre as diversas contas, complementando as conclusões obtidas por meio da análise horizontal. (MATARAZZO, 2017; ASSAF NETO e LIMA, 2010).

Em terceiro, a análise do capital de giro utiliza-se de índices que demonstram os movimentos dos recebimentos, pagamentos e estocagem para analisar os investimentos e financiamentos do capital de curto prazo das organizações. (ASSAF NETO, 2001; MATARAZZO, 2017)

Em quarto, destacamos a utilização do demonstrativo de fluxo de caixa. A partir do 2008 passou a ser obrigatório a utilização desse instrumento que fornece informações para uma análise profunda da situação financeira da empresa e da sua movimentação de caixa. (LEMES JR., RIGO E CHEROBIM, 2010; MATARAZZO, 2017)

Em quinto, há que se destacar as análises prospectivas. A tradição na análise de balanço é focar em informações que tratam do passado organizacional e com base nesse inferir o comportamento futuro. No final do século passado novas técnicas começaram se serem utilizadas para provisionar eventos organizacionais. Essas técnicas de análise prospectiva buscam 
incorporar novas variáveis que permite extrapolar a simples análise retrospectiva. (MATARAZZO, 2017)

Por fim, os modelos de análise de rentabilidade podem ser divididos em duas vertentes: um trata da análise da alavancagem financeira; a outra busca analisar a rentabilidade do capital investido, dissecando sua taxa em elementos que afetam seu desempenho. A análise por meio desse último, também chamado de Sistema Du Pont, procura identificar no conjunto de dados disponíveis no Balanço Patrimonial e Demonstração de Resultado do Exercício, as chamadas "áreas-chave" do desempenho financeiro da empresa. A vantagem do sistema é permitir a decomposição da rentabilidade em um componente associado às vendas, um componente de eficiência no uso de ativos e um componente de endividamento. (GITMAN, 2001; MATARAZZO, 2017).

Apesar de podermos separar os modos de análises, tal como apresentado anteriormente, atualmente há destaque para modelos integrados de análises econômico-financeiro que buscam organizar e condensar as informações, permitindo afastar a subjetividade do analista. Kassai (2002) destaca algumas técnicas de análise que buscam esse caminho: análises com teste de hipóteses, análise de regressão linear, análise discriminante, análise de regressão logística, análise fatorial, modelos de avaliação de desempenho, indicador de saúde econômico-financeiro das empresas.

Ainda, há que o surgimento no campo dos modelos estruturados de análise. Para Kassai (2002) este procedimento de análise propõe uma evolução, onde o modelo nutre-se de outras técnicas tradicionais, mas retira a subjetividade humana do julgamento. A análise tradicional ou qualitativa, que tem como foco a análise por meio dos índices, quocientes, entre outros, possui uma forte base no julgamento humano. Mas, as informações cunhadas no modelo tradicional de análise podem servir como bases para análises integradas, que se utilizam de modelos estatísticos, e análises estruturadas, como a Análise Envoltória de Dados (DEA) e Análise Estocástica. Assim, a análise de desempenho parte de um alto grau de envolvimento e interpretação humana para uma escala crescente de estruturação, que eliminam a subjetividade humana.

\section{Eficiência e a Análise Envoltória de dados}

Nos ambientes concorrenciais, tratar de eficiência e produtividade torna-se inevitável, dada a exigência, por parte dos competidores em gerenciar a escassez dos recursos disponíveis. Nesse sentido, existe a necessidade de uma técnica que permite a comparação das eficiências produtivas dos competidores envolvidos. 
Quanto aos termos produtividade e eficiência devemos reconhecer que os fundamentos dos termos têm características similares, mas elementos que os distinguem. O primeiro expressa um número absoluto enquanto o segundo traz uma grandeza relativa. Exemplificando, quando um único insumo (x) é usado para gerar um único produto (y), a eficiência é dada pela razão de y por x e a produtividade é o número dado por y (MATTOS e TERRA, 2015a; PASCOTTO, COMUNELO e CERETTA, 2018).

A primeira definição formal de produção eficiente é dada por Koopmans no ano de 1951 e metodologicamente desenvolvido por Debreu, em 1951, e Farrell, em 1957. A partir desses três marcos sabe-se que um processo de produção é eficiente quando emprega a menor quantidade possível de insumos (inputs) para uma dada produção (output) (eficiência econômica) ou quando obtém um maior nível de produção (output) com dado nível de recursos (inputs) (eficiência técnica). (ROSANO-PEÑA, 2012; BOUERI, 2015; PASCOTTO, COMUNELO e CERETTA, 2018).

Já quanto as técnicas, os modelos de análise de eficiência podem ser classificados em dois grandes grupos: os paramétricos e os não paramétricos. Os modelos de análise paramétricos avaliam a eficiência por uma relação funcional entre os recursos utilizados e a quantidade máxima de produtos produzidos, a partir dos parâmetros dessa função produção. Já as técnicas não paramétricas de análise da eficiência, como é o caso da Análise Envoltória de Dados (DEA), assumem hipóteses mais flexíveis sobre a distribuição das variáveis, e não exigem a especificação de uma função entre insumos e produtos. Assim, a possibilidade de produção é dada de modo mais indutiva, por meio do conjunto de todos os processos produtivos, estimado a partir das práticas observadas. Constrói-se a fronteira por meio da combinação linear das observações eficientes e mensura-se a eficiência a partir da distância que separa as unidades dessa fronteira. (ROSANO-PEÑA, 2012).

O desenvolvimento prático da técnica de Análise Envoltória de Dados se deu no ano de 1978 com a tese de doutorado de Edwardo Rhodes, com a orientação de Willian Wager Cooper, que desenvolveu uma comparação do desempenho dos alunos de escolas que participavam de um programa federal de apoio com escolas que não aderiram ao programa. Cooper então utilizou o método de programação matemática, partindo do conceito de eficiência técnica para a relação produto/insumo desenvolvido por Farrel no ano de 1957, para a construção de um modelo que contemple vários produtos e insumos para medir e comparar o desempenho das escolas.

O modelo inicial do DEA, desenvolvido pelos autores Charnes, Cooper e Rhodes (1978), denominado de CCR, pressupõe retornos constantes de escala, isso quer dizer que uma variação nos inputs produz uma mudança equiproporcional nos outputs. De outra maneira, se um aumento 
de $\mathrm{k} \%$ na utilização de todos os insumos aumenta os resultados na mesma proporção de k\% (BOUERI, 2015, MATTOS e TERRA, 2015b). Para melhor compreensão, a Figura 1 apresenta as fronteiras de eficiência de produção com rendimentos constantes de escala (FERCE). Sob o olhar do modelo CCR apenas a DMU C é considerada eficiente e as outras DMU's são consideradas ineficientes. Assim, para estimar a ineficiência das DMU's que estão fora da fronteira de eficiência (FERCE) o modelo CCR efetua uma projeção radial, como pode ser visualizado no movimento dos pontos G-Gb da Figura 1.

Entretanto, é possível que uma função de produção apresente outros tipos de retornos de escala além do retorno constante, ou seja, dependendo da quantidade de insumos que esteja sendo empregada para fins de produção uma DMU pode estar operando em retornos crescentes, decrescentes ou constantes. Se um aumento de $\mathrm{k} \%$ na utilização de todos os insumos aumenta o produto em mais do que $\mathrm{k} \%$, dizemos que a função de produção apresenta retornos crescentes à escala. Entretanto, se esse mesmo aumento produzir uma variação no produto menor do que k\%, dizemos que a tecnologia de produção apresenta retornos decrescentes à escala. (MATTOS e TERRA, 2015b). Na Figura 1, podemos visualizar que o trecho A-C(exclusive) apresenta retornos crescentes de escala; o ponto $\mathrm{C}$ apresenta o único trecho com rendimentos constantes de escala: e o trecho representado pelos pontos $\mathrm{C}$ (exclusive)-E apresentam rendimentos decrescentes.

Assim, dado que algumas unidades tomadoras de decisões podem estar operando com retornos variáveis, ou seja, não apenas constantes, mas podendo ser crescentes ou decrescentes, Banker, Charnes e Cooper, no ano de 1984, apresentam um modelo que inclui retornos variáveis de escala, o que forneceu a possibilidade de comparar unidades tomadoras de decisões com portes diferentes. Esse modelo é conhecido como BCC, em menção aos autores. Na Figura 1 a fronteira de eficiência do modelo de retornos variáveis de escala (RVE) é representado pela linha FERVE. Nesse os pontos A, B, C, D e E são considerados eficientes, por estarem na fronteira de produção, já as DMU's F e G são ineficientes. 
Figura 1: Fronteiras de Eficiência BCC e CCR

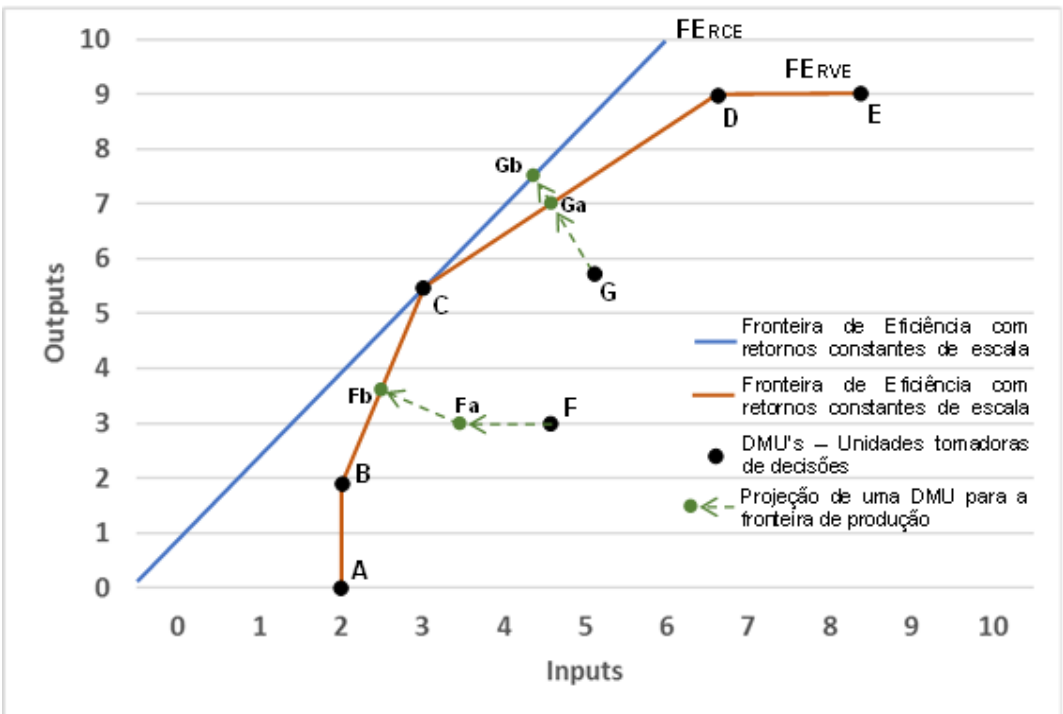

Fonte: Adaptado de Cooper Et. al. (2006, p. 116)

Comparativamente, os modelos $\mathrm{CCR}$ e BCC podem trazer resultados divergentes pois uma DMU por ser eficiente pelo BCC mas não pelo CCR. Isso ocorre devido o modelo CCR calcular a eficiência total, enquanto o modelo BCC calcula a eficiência técnica. Para se calcular a Eficiência de Escala, divide-se a Eficiência do modelo BBC (eficiência total) pela Eficiência do modelo BCC (eficiência técnica).

Como Boueri (2015) apresenta, ineficiência de determinada DMU pode ser estimada pela magnitude da projeção necessária para que ela alcance a referida fronteira (alvo), como já mencionado anteriormente. Essa projeção, que pode ser uma contração dos insumos ou uma expansão dos produtos, é realizada de forma proporcional. Por esse motivo é denominada projeção radial, pois sempre pode ser expressa como um raio partindo da origem, como pode ser vista na Figura 1, nos pontos G-Ga para o modelo BCC e G-Gb no modelo CCR.

Vale ainda mencionar que as unidades tomadoras de decisões (DMU's) podem estar operando com folgas, ou seja, utilizando insumos além do estritamente necessário, em excesso, ou com produção abaixo da adequada. Assim, na análise envoltória de dados a folga é expressada pelo movimento paralelo aos eixos das coordenadas da DMU ineficiente, ou seja, unidades que estão produzindo com a quantidade desnecessária de recursos ou aquém da quantidade recomendável. Esse movimento de folga pode ser compreendido no trecho F-Fa na Figura 1, onde que, por eliminação dos desperdícios a DMU consegue melhorar sua eficiência, pois produz o mesmo com menos. Assim, com a eliminação das folgas uma DMU consegue diminuir a o movimento radial para alcance do alvo, ou seja, da fronteira de eficiência (veja o 
ponto $\mathrm{Fb}$ na Figura 1). (BOUERI, 2015, MATTOS e TERRA 2015b, PASCOTTO, COMUNELO e CERETTA, 2018, e FERREIRA e GOMES, 2009).

Ainda, com a classificação das DMU's com eficiência técnica ou ineficiência técnica e nos tipos de retornos de escala possibilita a classificação dessas em seis tipificações. As DMU's com ineficiência de técnica com retorno de escala constante estão operando na escala ótima, mas existe ineficiência técnica, assim pode-se reduzir o uso dos insumos e continuar produzindo a mesma quantidade (orientação insumo), ou ainda, a produção pode crescer utilizando-se os mesmos insumos (orientação produto). Se possuir ineficiência técnica com retorno de escala crescente a DMU está abaixo da escala ótima (precisa aumentar a produção) e apresenta ineficiência técnica (há desperdício de recursos), necessitando aumentar a produção, reduzindo a quantidade de recursos empregadas. Por fim, a DMU's com ineficiência de técnica com retorno de escala decrescente está acima da escala ótima e apresenta desperdícios, necessitando eliminar os excessos na utilização dos recursos, ou seja, produzir mais com os mesmos recursos, e para ajustar-se a escala, precisa encontrar formas de melhorar sua produtividade, como investindo em tecnologia (FERREIRA e GOMES, 2009).

As DMU's com eficiência técnica com retorno de escala constante estão operando na melhor situação, assim o aumento da produção deve ocorrer mantendo-se a proporção de uso dos fatores e os aumentos de custos são proporcionais aos aumentos de produção. Se possuir eficiência técnica com retorno de escala crescente a DMU está operando sem desperdício de recursos, mas está abaixo da escala ótima, assim, um aumento da produção pode ocorrer através da incorporação de insumos, desde que seja mantida a relação entre quantidades de produtos e insumos. Por fim, a DMU's com eficiência técnica com retorno de escala decrescente opera sem desperdícios, mas acima da escala ótima, necessitando a adoção de políticas quantitativas que visem o aumento da produção sem a necessidade de se utilizar mais recursos, devendo reconhecer que aumentos na produção ocorrem a custos crescentes (FERREIRA e GOMES, 2009).

Em suma, a análise envoltória de dados foi utilizada nesta pesquisa para a análise e comparativo da eficiência econômico-financeira das organizações cooperativas agroindustriais por se caracterizar como uma técnica estruturada que permite comparar unidades de negócios com portes diferentes (em específico o modelo BBC) com uso de múltiplos inputs e outputs. Como resultados o modelo de análise permite separar as organizações eficientes das ineficientes, indica a eficiência de cada unidade, fornece indicativos para que cada unidade se torne eficiente, indica uma unidade espelho eficiente para cada unidade ineficiente e a contribuição de cada input e output para a eficiência. 


\section{Método}

Utilizou-se nesta pesquisa o emprego de uma pesquisa de abordagem quantitativa, pela a escolha de procedimentos sistemáticos para a descrição e explicação de fenômenos, e estratégia de pesquisa de levantamento, por buscar informações de um grupo significativo de organizações, conforme delineiam Creswell (2007), Richardson (2008) e Gil (2008).

As fontes de dados se pautaram em documentos financeiros, ou seja, demonstrativos de resultados, balanços patrimoniais e notas explicativas das organizações cooperativas no ano de 2016. O escopo da pesquisa se situou nas cooperativas agropecuárias listadas no ranking Valor 1000, desenvolvido pela revista Valor Econômico.

No levantamento inicial das empresas, conseguiu-se identificar que no Valor 1000 no setor agropecuário encontram-se 42 organizações, sendo que desta, um total de 35 são organizações cooperativas. Na sequência, buscou informações sobre seus demonstrativos financeiros. Como resultado a pesquisa conseguiu levantar as informações necessárias para 16 cooperativas, sendo elas: Coamo, Cooxupé, C.Vale, Cocamar, Lar, Integrada, Castrolanda, Coopavel, Coperalfa, Copercitrus, Frísia, Copagril, Copercampos, Capal, Holambra e Camda.

Análise dos dados se deu por meio da técnica de Análise Envoltória de Dados (DEA). O modelo BBC foi escolhido por permitir que a análise com unidades tomadoras de decisões de portes diferentes. Quanto à orientação, seguindo o pensamento de Kassai (2002), o presente estudo utilizou-se de uma orientação para os resultados (output), pois dadas as características dos investimentos feitos pelo setor em estudo, pois é difícil alocar ou reduzir os recursos (inputs).

A técnica de seleção de dados, seguindo a literatura que trata da análise financeira, utilizou-se o modelo de análise de rentabilidade, conhecido por Sistema Du Pont, para definir inicialmente os inputs e outputs. O sistema Du Pont busca identificar no conjunto dos dados da Demonstração do Resultado do Exercício e do Balanço Patrimonial, as chamadas áreas-chave do desempenho financeiro da empresa (inputs) e então obtém-se a medida síntese de rentabilidade organizacional, o retorno sobre o patrimônio líquido (ROE) (output).

Assim, inicialmente foram definidos os seguintes inputs: vendas líquidas, custos das mercadorias vendidas, despesas operacionais, despesas/receitas financeiras, impostos, ativo circulante, ativo realizável a longo prazo, ativo permanente, passivo circulante, passivo não circulante e patrimônio líquido. Entretanto, como o modelo é sensível à quantidade de variáveis, optou-se por sintetizar os dados de inputs conforme o modelo Du Pont desenvolve, assim, utilizou-se no modelo: sobras líquidas, ativo total, passivos e patrimônio líquido; e o output, que é o retorno sobre o capital empregado, o principal resultado dissecado pela técnica. Após, 
seguimos o pressuposto de que a seleção das variáveis deve obedecer ao princípio de máxima relação causal entre inputs e outputs, utilizou-se assim o método I-O Stepwise Exaustivo Completo, conforme as orientações de Senra, Mello e Meza (2007). Ao final, os inputs sobras, ativo total e patrimônio líquido e o output rentabilidade apresentaram significâncias para compor o modelo de análise.

Utilizou-se nesse estudo o software R, por ser um software livre e open source, com muitas extensões e funções de análise de dados, disponibilizadas em pacotes (packages) na internet. Entre esses, dedicados ao DEA, pode-se destacar o FEAR (Frontier Efficiency Analysis with R) e o Benchmarking, sendo esse o principal recurso computacional utilizado neste trabalho. Além disso, o $\mathrm{R}$ pode ser programado e novas bibliotecas podem ser criadas, possibilitando análises que vão além do escopo dos softwares dedicados exclusivamente aos modelos DEA. (BOGEOGETOFT e OTTO, 2011)

\section{Resultados e Discussão}

Na Tabela apresentado na sequência (Tabela 01) tem-se os valores e algumas estatísticas descritivas dos inputs e outputs do modelo. As Sobras Líquidas, que representa efetivamente os valores das vendas restantes após a computação de todos os custos e despesas inerentes (LEMES JÚNIOR, RIGO e CHEROBIM, 2010), têm apenas duas cooperativas, a Coamo e Cooxupé, que apresentam valores acima da média. Nesse podemos dar destaque para as sobras da Coamo, que foram cerca de 4,9 vezes maior que as do segundo lugar, a Cooxupé. Quanto à dispersão dos dados, no caso o input sobras líquidas pôde-se perceber uma grande dispersão, haja vista que o desvio padrão está cerca de $60 \%$ superior à média, porém boa parte dessa variação associa-se a Coamo, conforme já mencionado.

Tabela 1 - Descrição das variáveis

\begin{tabular}{llrrrr}
\multicolumn{1}{c}{ DMU's } & Nro. & \multicolumn{1}{c}{ Inputs } & \multicolumn{1}{c}{ PL* } & \multicolumn{1}{c}{ Output } \\
\hline Coamo & 1 & \multicolumn{1}{c}{ Robras* } & \multicolumn{1}{c}{ AT* } & \multicolumn{1}{c}{ * } \\
Cooxupé & 2 & $855.299,61$ & $8.526 .755,60$ & $4.194 .587,51$ & 20,39 \\
C.Vale & 3 & $175.280,43$ & $4.026 .292,33$ & $892.669,58$ & 19,64 \\
Cocamar & 4 & $107.154,53$ & $5.046 .851,61$ & $1.423 .957,91$ & 7,53 \\
Lar & 5 & $120.407,00$ & $2.728 .352,00$ & $913.270,00$ & 13,18 \\
Integrada & 6 & $119.371,90$ & $3.755 .950,71$ & $1.027 .115,10$ & 11,62 \\
Castrolanda & 7 & $71.756,57$ & $1.860 .879,63$ & $505.714,83$ & 14,19 \\
Coopavel & 8 & $46.013,00$ & $2.314 .059,00$ & $930.110,00$ & 4,95 \\
Coperalfa & 9 & $50.484,66$ & $1.460 .346,30$ & $288.117,51$ & 17,52 \\
Copercitrus & 10 & $107.998,97$ & $1.792 .316,80$ & $1.007 .596,24$ & 10,72 \\
Frísia & 11 & $90.450,00$ & $3.035 .189,00$ & $801.435,00$ & 11,29 \\
Copagril & 12 & $94.020,00$ & $2.100 .552,00$ & $732.221,00$ & 12,84 \\
Copercampos & 13 & $12.250,10$ & $1.016 .537,82$ & $266.980,63$ & 4,59 \\
Capal & 14 & $40.531,77$ & $1.172 .271,14$ & $372.662,69$ & 10,88 \\
Holambra & 15 & $41.465,61$ & $792.627,26$ & $298.018,74$ & 13,91 \\
Camda & 16 & $24.927,00$ & $549.000,00$ & $160.572,00$ & 15,52 \\
\hline
\end{tabular}

Fonte: Levantamento dos dados realizado pelos autores, 2018. Nota: *Valores em milhares. 
O input Ativo Total é a composição de todos os direitos e bens da organização. Essa variável apresentou seis empresas com valores acima dessa média, sendo a Coamo, C,Vale, Cooxupé, Lar, Copercitrus e Cocamar. Nessa variável há uma alta dispersão dos dados, apresentando um coeficiente de variação de 0,80 .

O último input utilizado no modelo, o Patrimônio Líquido, é o valor investidos pelos sócios na organização, ou seja, é o valor devido pela cooperativa aos seus donos. Esse input teve sete empresas que apresentaram valores acima da média, sendo elas Coamo, C.Vale, Lar, Coperalfa, Castrolanda, Cocamar e Cooxupé. O coeficiente de variação, de 1,08, destaca que há uma grande dispersão nessa variável.

O output presente no modelo, o Retorno do Patrimônio Líquido, que é uma medida de eficiência dos investimentos dos cooperados na organização cooperativa, apresentou uma média de retorno de $12,74 \%$ e nove cooperativas tiveram retornos acima da média (Coamo, Cooxupé, Coopavel, Holambra, Camda, Integrada, Capal, Cocamar e Frísia). Quanto a dispersão dos dados deste indicador, percebe-se uma baixa razão entre o desvio padrão e a média, ou ainda, o desvio padrão está cerca de $36 \%$ em relação à média, o que indica uma dispersão dos dados menos evidente que dos inputs.

Pode-se destacar que os valores apresentados pela cooperativa Coamo são significativamente maiores que das outras DMU's. Se for excluído essa unidade do conjunto de dados a média do lucro líquido, ativo total, patrimônio líquido e rentabilidade do capital próprio seriam R\$ 76.041,57; R\$ 2.157.439,64; R\$ 658.448,75 e 12,23; e seus coeficientes de variação seriam 0,57; 0,60; 0,55 e 0,33; respectivamente. Entretanto, apesar de reconhecer que a Coamo afeta significativamente os resultados das médias e a dispersão do conjunto, decidiu-se por não a excluir pois o modelo BBC permite a análise com unidades tomadoras de decisões de portes diferentes (MATTOS e TERRA, 2015; BOUERI, 2015).

Na Tabela 2 apresenta-se os dados da eficiência técnica (EF) com retornos constantes de escala (RCE), rendimentos variáveis de escala (RVE), eficiência de escala (EE), o tipo de rendimento de escala no qual a organização está operando (constante, crescente ou decrescente) e se se a cooperativa possui ineficiência técnica (IT) e ou ineficiência de escala (IE). Quanto à análise de eficiência técnica pura, que é representa por ETRVE, e eficiência de escala, EE, podese destacar que apenas a cooperativa Holambra é considerada eficiente. Já a Coamo, Cooxupé, Coopavel e Copagril são consideradas eficientes tecnicamente, mas possuem ineficiências de escala. As outras cooperativas possuem ineficiência técnica e ineficiência de escala.

De modo mais específico quanto à eficiência técnica, as organizações estudadas tiveram uma média de $76,4 \%$ e desvio padrão de 22,5\%. Das 11 cooperativas com ineficiência técnica, 
três (Camda, Capal e Integrada) tiveram indicadores maiores que a média, já as outras oito cooperativas possuem um índice de eficiência menor que a média. Ainda, devemos destacar, conforme apresenta Boueri (2015) eficiência medida pelo modelo de retornos variáveis de escada deve ser considerada o parâmetro de eficiência técnica, pois mede a relação entre a produção efetiva da DMU e a sua produção potencial dada a escala de produção.

A eficiência de escala (EE) no conjunto dos dados estudados teve uma média de $46,7 \%$ e desvio padrão de 25,2\%. Das 15 cooperativas com ineficiência de escala, ou seja, aquelas que não estão produzindo na escala apropriada, a Castrolanda, Copagril, Coopavel, Copercampos, Capal e Camda tiveram um indicador maior que a média. As outras nove cooperativas registraram um índice menor.

Tabela 2 - Resultados do DEA - Retornos de Escala e Ineficiências

\begin{tabular}{llllllc}
\hline DMU's & $\begin{array}{l}\text { Nro. } \\
\text { DMU }\end{array}$ & $\begin{array}{l}\text { ET } \\
\text { (rce) }\end{array}$ & $\begin{array}{l}\text { ET } \\
\text { (rve) }\end{array}$ & EE & $\begin{array}{l}\text { Tipo } \\
\text { rendimento }\end{array}$ & $\begin{array}{l}\text { Ineficiência Técnica (IT) e/ou } \\
\text { Ineficiência de Escala (IE) }\end{array}$ \\
\hline Coamo & 1 & $8,5 \%$ & $100,0 \%$ & $8,5 \%$ & Decrescente & IE \\
Cooxupé & 2 & $22,8 \%$ & $100,0 \%$ & $22,8 \%$ & Decrescente & IE \\
C.Vale & 3 & $11,3 \%$ & $40,7 \%$ & $27,7 \%$ & Decrescente & IT e IE \\
Cocamar & 4 & $17,6 \%$ & $71,0 \%$ & $24,8 \%$ & Decrescente & IT e IE \\
Lar & 5 & $15,6 \%$ & $62,2 \%$ & $25,1 \%$ & Decrescente & IT e IE \\
Integrada & 6 & $31,8 \%$ & $79,5 \%$ & $40,0 \%$ & Decrescente & IT e IE \\
Castrolanda & 7 & $17,3 \%$ & $28,8 \%$ & $59,9 \%$ & Decrescente & IE \\
Coopavel & 8 & $62,9 \%$ & $100,0 \%$ & $62,9 \%$ & Decrescente & IT e IE \\
Coperalfa & 9 & $21,2 \%$ & $60,2 \%$ & $35,1 \%$ & Decrescente & IT e IE \\
Copercitrus & 10 & $20,0 \%$ & $62,0 \%$ & $32,3 \%$ & Decrescente & IE \\
Frísia & 11 & $21,9 \%$ & $71,1 \%$ & $30,8 \%$ & Decrescente & IT e IE \\
Copagril & 12 & $60,2 \%$ & $100,0 \%$ & $60,2 \%$ & Crescente & IT e IE \\
Copercampos & 13 & $43,1 \%$ & $65,0 \%$ & $66,3 \%$ & Decrescente & - \\
Capal & 14 & $62,1 \%$ & $86,6 \%$ & $71,6 \%$ & Decrescente & IT e IE \\
Holambra & 15 & $100,0 \%$ & $100,0 \%$ & $100,0 \%$ & Constante & Decrescente \\
Camda & 16 & $74,8 \%$ & $94,7 \%$ & $79,0 \%$ & IT &
\end{tabular}

Fonte: Compilação dos resultados obtidos pelos autores no software R, 2018.

A ineficiência de determinada DMU pode ser estimada pela magnitude da projeção necessária para que ela alcance a referida fronteira (BOUERI, 2015). Essa projeção, que pode ser uma contração dos insumos (orientação para insumos) ou uma expansão dos produtos (orientação para produtos), que é foco desta pesquisa, é realizada de forma proporcional. Ainda, há de se destacar que algumas unidades tomadoras de decisões podem estar operando com excesso de insumos (folgas) o que possibilita interceptar a fronteira de eficiência num movimento paralelo aos eixos das coordenadas reduzindo a quantidade de insumos e paroduzindo a mesma quantidade.

A Tabela a seguir (Tabela 3) apresenta o movimento radial, folga e alvo que as cooperativas devem alcançar para serem consideradas eficientes. Primeiramente devemos levar em conta nenhuma DMU possui folgas para alcance do alvo. Assim os alvos se tornam os movimentos radiais. A média dos retornos alvo são 16,9 e um desvio padrão de 3,5. Ainda, pode- 
se dar destaque ao retorno de 4,6 da cooperativa Copagril, que possui eficiência técnica, pelo menor valor apresentado na série.

Vale mencionar que a projeção necessária para uma DMU alcançar a fronteira sempre tem como referência outros pontos, ou seja, os pontos que dão origem ao trecho da fronteira sobre o qual a projeção de um determinado ponto recai. Esses formam o conjunto de referência da DMU em questão. Para identificá-las, deve-se encontrar os valores calculados para o vetor $\chi$ (lambda) (Boueri, 2015).

Tabela 3 - Resultados do DEA - Projeção e Benchmarks

\begin{tabular}{|c|c|c|c|c|c|c|c|c|c|c|c|}
\hline \multirow{2}{*}{ DMU's } & \multirow{2}{*}{$\begin{array}{l}\text { Nro. } \\
\text { DMU }\end{array}$} & \multirow{2}{*}{ ETRVE } & \multirow[b]{2}{*}{$\mathbf{y}$} & \multirow{2}{*}{ Radial } & \multirow{2}{*}{ Folga } & \multirow{2}{*}{ Alvo } & \multicolumn{5}{|c|}{ Benchmarks } \\
\hline & & & & & & & 1 & 2 & 8 & 12 & 15 \\
\hline Coamo & 1 & $100,00 \%$ & 20 & 20,4 & 0 & 20,4 & 1 & - & - & - & - \\
\hline Cooxupé & 2 & $100,00 \%$ & 20 & 19,6 & 0 & 19,6 & - & 1 & - & - & - \\
\hline C.Vale & 3 & $40,70 \%$ & 7,5 & 18,5 & 0 & 18,5 & - & 0,5 & 0,5 & - & - \\
\hline Cocamar & 4 & $71,00 \%$ & 13 & 18,6 & 0 & 18,6 & - & 0,5 & 0,5 & - & - \\
\hline Lar & 5 & $62,20 \%$ & 12 & 18,7 & 0 & 18,7 & - & 0,5 & 0,5 & - & - \\
\hline Integrada & 6 & $79,50 \%$ & 14 & 17,9 & 0 & 17,9 & - & 0,2 & 0,8 & - & - \\
\hline Castrolanda & 7 & $28,80 \%$ & 5 & 17,2 & 0 & 17,2 & - & - & 0,8 & - & 0,2 \\
\hline Coopavel & 8 & $100,00 \%$ & 18 & 17,5 & 0 & 17,5 & - & - & 1 & - & - \\
\hline Coperalfa & 9 & $60,20 \%$ & 11 & 17,8 & 0 & 17,8 & - & 0,1 & 0,9 & - & - \\
\hline Copercitrus & 10 & $62,00 \%$ & 11 & 18,2 & 0 & 18,2 & - & 0,3 & 0,7 & - & - \\
\hline Frísia & 11 & $71,10 \%$ & 13 & 18 & 0 & 18 & - & 0,2 & 0,8 & - & - \\
\hline Copagril & 12 & $100,00 \%$ & 4,6 & 4,6 & 0 & 4,6 & - & - & - & 1 & - \\
\hline Copercampos & 13 & $65,00 \%$ & 11 & 16,7 & 0 & 16,7 & - & - & 0,6 & - & 0,4 \\
\hline Capal & 14 & $86,60 \%$ & 14 & 16,1 & 0 & 16,1 & - & - & 0,3 & - & 0,7 \\
\hline Holambra & 15 & $100,00 \%$ & 16 & 15,5 & 0 & 15,5 & - & - & - & - & 1 \\
\hline Camda & 16 & $94,70 \%$ & 15 & 15,9 & 0 & 15,9 & - & - & 0,2 & - & 0,8 \\
\hline
\end{tabular}

Fonte: Compilação dos resultados obtidos pelos autores no software R, 2018.

A Tabela 3 também apresenta o resultado das DMU's de referência (benchmarks) e a proporção de referência para as unidades não eficientes (lambdas). As cooperativas Coamo, Cooxupé, Coopavel, Copagril e Holambra, que são consideradas DMU's com eficiência técnica, possuem elas mesmas como referência. Já todas as unidades ineficientes possuem outras duas cooperativas como referência. As cooperativas Cooxupé, Coopavel e Holambra são as únicas cooperativas eficientes que aparecem como referência para as DMU's ineficientes, sendo a Coopavel a que mais se destaca, com 11 referências.

Ainda, sabe-se que as DMU's podem estar operando em um dos três diferentes tipos de rendimentos. Para identificação do tipo de rendimento, pode-se utilizar o método Seiford-Zhu, onde DMU's com eficiência de escala igual a 1 opera com rendimentos constante de escala, já DMU's que possuem um valor do somatório dos lambdas ótimo calculados com rendimentos constantes de escala (RCE) menor que um, possui um rendimento crescente de escala, e se este for maior que um, tem-se um rendimento decrescente de escala (COOPER, Et. al. 2006). Estes tipos de rendimentos de escala estão apresentados na Tabela 02. 
Pode-se dar destaque para a cooperativa Holambra por possuir retorno de escala constante e ter eficiência técnica e de escala. Pois, conforme apresenta Ferreira e Gomes (2009), essa organização está utilizando os recursos sem desperdício e opera em escala ótima. O aumento da produção deve ocorrer mantendo-se a proporção de uso dos fatores.

A cooperativa Copagril possui eficiência técnica, ineficiência de escala e retorno de escala crescente. Isso indica que apesar de tecnicamente eficiente, ou seja, não existem insumos utilizados em excesso, o volume de produção está abaixo da escala ótima. Assim, a cooperativa pode aumentar a produção em custos decrescentes. $\mathrm{O}$ aumento da produção deve ocorrer mediante incorporação de insumos, porém mantendo-se as relações entre as quantidades de produtos e insumos. (FERREIRA e GOMES, 2009)

As cooperativas Coamo, Cooxupé, Coopavel têm eficiência técnica, ineficiência de escala e possuem retornos de escala decrescentes. Essas características indicam que essas DMUs operam sem desperdícios, porém acima da escala ótima. Isso quer dizer que um aumento da produção ocorrerá a custos crescentes. De outro modo, devem-se aplicar políticas qualitativas para aumentar a produtividade sem a incorporação de mais insumos. (FERREIRA e GOMES, 2009)

Por fim, onze cooperativas pertencem ao mesmo grupo, sendo elas: C. Vale, Cocamar, Lar, Integrada, Castrolanda, Coperalfa, Coopercitros, Frísia, Copercampos, Capal e Camda; que possuem ineficiência técnica, ineficiência de escala e retornos de escala decrescentes. Assim é necessário, conforme apresentam Ferreira e Gomes (2009), corrigir as duas ineficiências. Para aumentar a eficiência técnica devem-se eliminar o excesso de utilização dos insumos, o que equivale a produzir mais e com os mesmos insumos. Com relação à escala, pode-se melhorar a tecnologia, aumentando a produtividade dos fatores de produção ou insumos.

\section{Considerações Finais}

As cooperativas agroindustriais brasileiras, inseridas em um mercado capitalista e concorrencial, precisam manter-se atualizadas e buscando melhorias na eficiência em diversos sentidos, já que seus associados estão sempre à procura das maiores vantagens. Nesse sentido esse trabalho possibilitou descrever suas eficiências, apontou aspectos a serem observados, quanto a eficiência técnica e de escala e metas a serem perseguidas.

A utilização do modelo DEA com retorno variável de escala (BCC) permitiu verificar que 11 das 16 cooperativas analisadas apresentaram ineficiência técnica e de escala e retornos decrescentes de escala. Isso significa que todas precisam se adequar quanto à utilização de 
recursos e às condições concorrenciais do mercado, tendo em vista a competitividade e estrutura do setor.

Entre as cooperativas eficientes em escala e tecnicamente, destacou-se a Coopavel, por ter sido mencionada como referência para 11 cooperativas, seguida da Cooxupé com 7 aparições e Holambra com 4. Entre as ineficientes, pode-se destacar a Castrolanda com uma eficiência técnica de apenas $28,8 \%$ e C.Vale com $40,7 \%$.

Vale destacar que a cooperativa Coamo, por ser detentora de $42,85 \%$ da soma das sobras líquidas, 20,85\% da soma do ativo total e 29,81\% da soma do patrimônio líquido, e uma rentabilidade de 20,39\%, no modelo tradicional de análise financeira, onde se tem a base da subjetividade humana no julgamento, seria uma organização de referência. Entretanto, na Análise Envoltória de Dados apresentou uma pífia eficiência de escala, apenas $8,5 \%$ e não é apontada como modelo (benchmark) para nenhuma outra cooperativa ineficiente. Isso mostra a importância dos métodos de análise que, como a DEA, baseiam-se num conjunto amplo informações para que, a partir de um processo estruturado metodologicamente, forneçam informações importantes para a tomada de decisões.

A Copagril foi única cooperativa que apresentou retornos crescentes de escala e eficiência técnica. Para essa cooperativa, investimentos para ampliar a produção, desde que mantidas as proporções entre insumos e produtos, trará retornos mais que proporcionais aos investimentos.

Apesar de as cooperativas não terem como objetivo o acúmulo de capital e o crescimento a todo-custo, estão inseridas em um mercado altamente competitivo e para manterem-se nele, precisam almejar a eficiência na prestação dos serviços que se propuseram a oferecer. Tal como apresenta Bialoskorski Neto (2014), em face do fortalecimento da concorrência essas organizações necessitam ser ágeis, com estruturas enxutas, preocupadas com o processos e redução de desperdícios.

\section{Referências}

ASSAF NETO, A. Estrutura e Análise de Balanços: um enfoque econômico-financeiro. $6^{\circ}$ ed. São Paulo: Atlas, 2001.

ASSAF NETO, A. Finanças Corporativas e Valor. São Paulo: Atlas, 2014.

ASSAF NETO, A.; LIMA, F. G. Fundamentos de administração financeira. São Paulo: Atlas, 2010.

BANKER, R. D.; CHARNES, A.; COOPER, W. W. Some Models for Estimating Technical and Scale Inefficiencies in Data Envelopment Analysis. Manegement Science, v. 30, n. 9, p. 1078 1092, September 1984. 
BIALOSKORSKI NETO, S. Agronegócio cooperativo. In: BATALHA, M. O. (coord.) Gestão agroindustrial. $3^{\circ}$ ed. São Paulo: Atlas, 2014.

BOGETOFT, P., OTTO, L. Benchmarking with DEA, SFA and R. Springer, 2011.

BOUERI, R. Modelos não paramétrico: Análise Envoltória de Dados (DEA) In: BOUERI, R.; ROCHA, F.; RODOPOULOS, F. (organizadores) Avaliação da Qualidade do Gasto Público e Mensuração da Eficiência. Brasília: Secretaria do Tesouro Nacional, 2015.

BRASIL. LEI N ${ }^{\circ}$ 5.764, DE 16 DE DEZEMBRO DE 1971. Define a Política Nacional de Cooperativismo, institui o regime jurídico das sociedades cooperativas, Brasília,DF, dez. 1971.

COOPER W. W.; SEIFORD L. M.; TONE K. Introduction to Data Envelopment Analysis and Its Uses. Springer Science, 2006.

CRESWELL, J. W. Projeto de pesquisa: métodos qualitativo, quantitativo e misto. Porto Alegre: Artmed, 2007.

FERREIRA, C. M.de C.; GOMES, A. P. Introdução à análise envoltória de dados: teoria, modelos e aplicações. Viçosa: Editora UFV, 2009.

GIL, A. C.. Como elaborar projetos de pesquisa. 4. ed. São Paulo: Atlas, 2007.

GITMAN, J. Princípios da administração financeira. Porto Alegre: Bookman, 2001.

KASSAI, S. Utilização da Análise por Envoltória de Dados na Análise de Demonstrações Contábeis. Tese de doutorado em Contabilidade - Universidade de São Paulo, São Paulo, 2002.

MATARAZZO, D. C. Análise financeira de balanços: uma abordagem gerencial. $7^{\circ}$. ed. São Paulo: Atlas, 2017.

MATTOS, E.; TERRA, R. Conceitos sobre eficiência. In: BOUERI, R.; ROCHA, F.; RODOPOULOS, F. (organizadores) Avaliação da Qualidade do Gasto Público e Mensuração da Eficiência. Brasília: Secretaria do Tesouro Nacional, 2015a

MATTOS, E.; TERRA, R. Fundamentos microeconômicos da mensuração da eficiência. In: BOUERI, R.; ROCHA, F.; RODOPOULOS, F. (organizadores) Avaliação da Qualidade do Gasto Público e Mensuração da Eficiência. Brasília: Secretaria do Tesouro Nacional, 2015b

OCB - ORGANIZAÇÃO DAS COOPERATIVAS BRASILEIRAS. Ramos do Cooperativismo. Disponível em: 〈http://www.ocb.org.br/ramos >. Acesso em: 30 de março de 2018

OCEPAR. Ramos do Cooperativismo Brasileiro. Disponível em: <http://www.paranacooperativo.coop.br/ppc/>. Acesso em: 30 de março de 2018.

PASCOTTO, H.; COMUNELO, A. L.; CERETTA, G. F., Eficiência técnica na aplicação de recursos públicos $\mathrm{Na}$ área da saúde dos municípios do sudoeste do Estado do paraná. Gestão e Desenvolvimento em Revista. V. 4, N. 1, jan-jun/2018, p. 21-37

RICHARDSON, R. J. Pesquisa Social. $3^{\circ}$ ed. São Paulo: Atlas, 2008.

ROSANO-PEÑA, C. Eficiência e impacto do contexto na gestão através do DEA: o caso da UEG. Produção, Brasília, DF, v. 22, n. 4, p. p. 778-787, set./dez. 2012.

SENRA, N.; MELLO, S. de; MEZA, A. Estudo sobre métodos de seleção de variáveis em DEA. In: Pesquisa Operacional, v.27, n.2, p.191-207, Maio a Agosto de 2007.

Recebido em 01/05/2020 - Aprovado em 20/06/2020. 